\section{The Reality Is ... Everyone Is Selling Something}

\author{
Diane H. Smith, Guest Columnist \\ Diane H. Smith is Associate University Librarian, \\ Research and Educational Services, George \\ Mason University, Fairfax, Virginia. \\ Correspondence concerning this column should \\ be addressed to Marianne Ryan, Associate \\ University Librarian for Public Services, Northwestern \\ University, 1970 Campus Drive, Evanston, IL 60208; \\ email:marianne-ryan@northwestern.edu.
}

Vendors: Can't live with them; can't live without them. So more often than not, librarians view engaging with company representatives as a necessary evil and just put up with them. But these relationships don't have to be adversarial and, in fact, can be ones of mutual learning and shared growth that benefit everyone involved. In this column, Diane H. Smith suggests a constructive approach to managing these important relationships. As someone who has been both a librarian and a vendor, she offers valuable insights from both sides of her experience. Smith posits that, in the end, we all share the goal of effectively selling the library to its constituents, and ultimately, we're all in this together-Editor

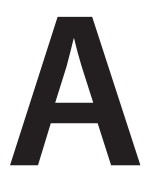
lmost twenty years ago I was offered the opportunity to leave academic librarianship and work for a well-respected library information provider. At the time, this move to the "dark side" was a simple decision driven by family needs, and it turned out to be an adventure that was both professionally rewarding and highly educational. I have recently reentered the "light side" of academia and at times have found the cultural change a challenge to overcome. I had forgotten many of the professional quirks of academic librarianship, and my "corporate" management style has, no doubt, been disturbing to some.

One thing that my business experience instilled within me is a much better appreciation for what it takes to build, maintain, and sell a product to libraries. Because I managed product development and market research and consequently interacted with both customers and our sales force, I understand the motivations and thought processes of each group. I also know that interacting with account executives (the terms "account executive," "sales person," and "sales rep" are used interchangeably throughout this article) is not something that all librarians relish. The goal of this article is to provide some background that will help you understand the world of academic library sales and manage your vendor relationships in a productive manner. In all honesty, the sales process is the same no matter the product. Each industry has its variations and quirks, but the principles are the same. I also share some pointers that might improve your working relationships with the account executives who visit you. Finally, if you may have been thinking that working on the dark side looks easy and is of interest, this article may inform career choices. 


\section{DEMOGRAPHICS OF THE US ACADEMIC LIBRARY MARKET}

When it comes to library sales, the first thing you need to know is that the US academic library market is not a growing market; in fact, if it is anything, it is a shrinking one. Brand new colleges and universities that need library resources are simply not being founded. Even law schools, the only segment of the higher education market that actually had new schools being established recently, is now in decline due to a glut of unemployed attorneys. ${ }^{1}$ Not only is the academic library market shrinking, but also funding to this market has been severely cut in the past few years because of the US economic downturn.

Given this reality, it probably isn't surprising that business can often be challenging and, consequently, that sales reps may seem pushy. All companies have a primary goal to grow. How can library vendors grow their businesses in such an environment? There are four primary ways. First, they can buy competitive or complementary companies, thereby increasing their market share of a stagnant or declining market; the last few years have seen many of these acquisition growth actions. Second, they can grow organically by developing services that effectively outsource library operations to private companies. Approval plans and cataloging services are old examples of this strategy; discovery and the new generation ILS systems are current ones. The result is a transfer of library operational dollars (and staff positions) to automation services. A third way to grow revenue is to take away an account from a competitor. Called the "general reference wars" by a former colleague, this approach generally pits the large journal aggregators against each other, and these battles result in vendors working long and hard to convince customers to switch service providers. This strategy usually involves selling on price and content and is not unlike the phone/cable/ Internet provider struggles that you probably have personally encountered. The fourth strategy is to expand the market by creating a new product, either through digitizing a collection of material that an academic library might wish to acquire or by creating a brand new content package.

No matter the strategy, all four of these growth tactics require a sales force.

\section{SALES}

"Salesmanship, too, is an art; the perfection of its technique requires study and practice"

$$
\text { —James C. Penney }
$$

Although James C. Penney, founder of J.C. Penney, thought sales an art, there are many who feel it is a science that can be taught. There are hundreds of books on how to sell, replete with techniques and strategies to win an account. If you don't believe it, just run a quick Amazon search. From my experience, sales executives usually espouse one or two techniques that they want their sales force to follow. Using a core-sales technique/system gives all within the company a common vocabulary by which to communicate and to measure sales productivity, a handy thing to have when you are running a for-profit business.

Depending on the company's sales philosophy, it may hire different types of sales reps to support the product lines or to grow the business. Depending on the company and the breadth of its products, there may be more than one sales person visiting a library, so care needs to be taken not to undermine a colleague's products. Within the sales profession one way to characterize the two types of reps is as "hunters" and "farmers/gatherers." Hunters are valued for their ability to ferret out money and then create a strategy for making the sale. In library sales, hunters tend to be interested in large, one-time monographic sales or the sale of a significant serial obligation. Farmer/gatherers, on the other hand, are valuable because they continue to reap the benefit of a sale for a company by keeping the customer happy. These are the company representatives who will see that all your questions about a purchase are answered after the sale. They will arrange training; they will periodically check up to be sure that you are still happy with the product; and most importantly, they will work to guarantee that you will not cancel their company's product because another vendor has come along with an appealing competitive offer. I once knew a farmer sales rep who used the analogy of a "country peddler"; he traveled from school to school carrying the news, educating customers on new trends that he had observed or interesting tidbits that he could share, entertaining the staff, and generally building a positive relationship with the librarians in his territory. The relationships that he was tending were crucial to the economic health of the company, and every year he and his company reaped the benefits of his work.

Another way to characterize reps is by knowledge of their products. Consider yourself very lucky if you have an account person who knows the products and who can answer most of your questions. Depending on the company, the rep may simply have too many products to know all the details of each one and must bring product specialists into the sales process. Realistically, do you know in-depth content details about every database that your library purchases? It is reasonable to expect that the rep should know all aspects of the interface and how it works. And sometimes there are reps who are simply interested in making a sale and have little curiosity about the library or its business. A friend of mine once characterized these as the "slick, good looking, smooth talking, shiny shoed, gum-smacking sales reps" who sold totally on personality, not on product knowledge. These reps espouse the product demonstration philosophy of "three to know and three to show" (a PowerPoint demo with three marketing messages and three examples of how the product can be used). If you ask them a question beyond their very limited product knowledge, they are stymied. Fortunately, most of them don't last long in library sales. If you encounter this type of rep, a polite suggestion that they learn the product line might be in order. 


\section{A DAY IN THE LIFE OF A SALES REP}

Selling to academic libraries seems, in many ways, a charmed life: The customers are generally polite; the college environment is pleasant; there is no 9-5 routine and no office cubical. The typical librarian only experiences the sales presentation and perhaps an individual meeting. It all looks so easy it is natural to ask, "Is that all you do?"

Prospecting, cold calling, researching accounts, staying abreast of competitive products, developing an understanding of the trends within the world of academic librarianship, and doing paperwork take up a good part of the daily activities in the life of a typical academic sales rep. And then there is the travel. Depending on the company and the number of products, the territory is at a state or regional level. Think about it: academic libraries generally are not situated near other academic libraries unless they are in a large urban area, so figuring out how to effectively and efficiently visit customers, set up appointments, and make travel arrangements takes up a good deal of time.

Once at the library, the rep tries to meet with all the people who might be interested in the product line. This may mean many meetings with a wide range of individuals, ${ }^{3}$ and it can easily take up a whole day in travel, meetings, and presentations. Information about these meetings, such as who attended, any follow-ups, and any emails or phone conversations, is generally expected to be reported through a customer relations management system (CRM). Depending on the system, this can be a labor-intensive effort that offers management metrics on sales personnel activities. To put this into a librarian context, imagine having to report every interaction that you have on a daily basis with faculty and students at the end of each day.

Sales reps have one simple objective when they meet with potential customers: to understand the mission and strategy of the library from both a collection and service perspective, and then to uncover the library's long- and shortterm information needs. From this discussion, which is essentially a reference interview, the rep hopes to find a solution within the product line that will meet the library's goals. The reality is that, for most libraries, new products are "nice to have," not "must have" items. Through conversation, providing a trial, and responding to questions and addressing objections, the rep tries to position the proposed product near the top of the library's must-have list. Through these interactions, the rep is also trying to determine whether the library really can find the money to invest and who the deciders truly are.

\section{WHAT MOTIVATES SALES?}

The answer to this question is very simple-money and competition. Top sales people are by nature highly competitive. The desire to best one's colleagues is a huge driver. Another incentive, depending on the depth of the relationship the rep has forged with customers, is the desire to help. Some of the best reps that I have known truly cared about their customers and fought to get the best deal and the best product possible for them. A good sales person will report back on customersuggested product changes that could strengthen the offering, will push for contracts to go through legal review quickly, and will petition for discounts to lower the price. All these actions move reps closer to their goal, which in turn helps insure their continued employment, increases their potential to move toward a higher commission rate, and further cements relationships for future sales.

Throughout this process, they are focused on filling their pipeline and closing sales to meet goals. The pipeline analogy is one of movement through a system; it can also be referred to as the "sales funnel." In either situation, the concept is to pull sales along through the system to completion. Given the cyclical and sometimes precarious funding levels in academic libraries, it is difficult to guarantee when and if an order will come through. Thus it is very important that reps have many quotes at various stages in the sales process in an effort to meet their goals. Depending on the product, an offer may stay in the pipeline for years before being funded. Patience and a positive attitude are important for a rep.

So how are goals established? Goals are determined from the company's revenue expectations for the year. Goals are assigned annually, and reps are expected to find money in their respective sales territories, which have been established by sales management. Depending on the company, there may be both a new-order goal and a subscription-maintenance goal. Territories are usually carved out on the basis of an analysis of library budgets, past buying patterns, and a rep's home location. The goal in establishing territories is to provide a semi-level playing field for sales personnel with the caveat that individual goals may vary and be dependent on the territory's potential.

But what about the money? Like most things in life, it can be very good or very bad-in this case dependent on the company's sale's policies and an individual's abilities. Management tries to incentivize its sales force in various ways. Incentives can be added throughout the year to encourage the sale of specific product lines or to increase sales for a particular quarter or month. Sales management uses such incentives as tools to try to smooth out sales that can be very cyclical. Some companies pay a base salary with a variable commission. Some pay a low base salary and add a monthly payout called a "draw." Good reward systems are set up to encourage reps not only to hit, but to surpass, territory goals, usually through commission or bonus schemes. The closer to the goal, the more commission is earned per sale.

\section{WHAT CAN YOU DO TO HELP MANAGE THE RELATIONSHIP?}

Now that you understand what the rep is trying to accomplish in a visit, what part can you play in building a successful relationship? First and foremost, don't string the rep along with the 
hope of a sale if you know that the product will not be funded now or is simply not of interest. Librarians tend to be very polite and don't want to hurt a rep's feelings. Sometimes they hide behind the excuse that the "database committee" has to make a decision. Simply tell the rep the truth and explain why the product is not a high priority. Honesty is the best policy here; the rep will appreciate your directness. Remember, the rep needs to close sales and having "ghost" sales in the pipeline that aren't going to come to fruition isn't really helping.

If you know there are other liaisons or selectors who would be interested in a product, suggest that the rep meet with them; connecting the right people benefits everyone. If there is no money right now, but there is a strong need for the product, ask the rep for a pro forma invoice just in case a future windfall should quickly happen. The rep will understand that there are no guarantees, but it might help you purchase the product should the stars align and funding suddenly becomes available. If you know that someone else is the decision maker and you feel the product should be purchased, suggest a meeting between the rep and that person.

All libraries have funding issues, and every rep understands the current economic situation. I know that it is very tempting to just say "we have no money" as a way to shoo off the sales rep. But really that statement isn't true. I worked with someone who would always point out, "If the lights are on and the water is running, there is money-it is simply that our product is not on the priority list." And this brings us to one of the reasons that good sales reps maintain regular contact with their customers-it is to keep them informed about changes to products and services and to stay informed about the library's goals and changing objectives. Since it is a librarian's professional responsibility to keep up with new products, emerging technologies, and new services, one of the quickest and easiest ways to do that is to meet with sales people. Keep track of reps who do maintain routine contact with your library because they understand the market dynamics and have the personal investment required to provide the service level necessary to meet their customers' changing needs. Personally, I would be leery of reps that only appear when the money is flowing; these are the "good time Charlies" just looking for a quick sale.

If a sales rep brings a manager or vice-president in tow, use the session to raise your primary customer service issues and talk about your library strategy in detail. The more people within a business who you can touch, the better opportunity you will have to get problems solved and your library's agenda front and center with one of your suppliers.

When a rep calls for a meeting, find out the objectives for that meeting and make sure that you indicate how much time you can allot. If you know the agenda topic and there are others who are interested, suggest that they, too, be invited and offer to coordinate the meeting. This may well eliminate the need for a future meeting, save time all around, and help develop a positive relationship with the rep.

When there is a vendor presentation at your library, if you agree to attend, please show up. Reps usually try to create presentations that are tailored to your school; if they make that effort, the least you can do is attend. If you have access to a computer during the presentation, please don't read email, Twitter, or Facebook. This should be obvious, but I have personally seen the behavior on several occasions. Consider how you feel when you are teaching a class and students behave that way. Ask questions about how the product works, what it contains, and how it differs from competitive products. Any reps worth their salt should be able to answer these questions and will welcome your participation.

When you meet with reps, ask them questions about what they do. Remember, they are trying to build a relationship with you; you may as well build one, too. Talk to them about their approach to selling; find out what strategies work for them. You might learn approaches that work and ones that don't. Ask them what their typical day is like. See if you can figure out whether they are "hunters" or "gatherers." Ask them about their territory: How big is it and what schools did they last visit? Who are their best accounts? How do those schools fund these products? What innovative services do they see when they visit other places? Remember, they are traveling about in their territories and see a lot more libraries than you do. Use them as the "peddler" who brings news of activities in other places from which you could learn. Use the opportunity when they talk about products to educate them about competitive products that your library is considering. Educating them to the realities of the marketplace will guarantee that they share this information with their product development group and push to improve their products to increase the likelihood that there will eventually be a sale. By helping them in their sales efforts, they will work harder to get you the best deal and the best product, when and if you decide to buy.

\section{CONCLUSION}

Why does any of this matter? And how does all of this relate to you in your job? Whether you view it this way or not, in all likelihood you are constantly selling your library and its services to students and faculty, campus administrators, potential donors, and (if you are at a public institution) legislators. My experience on both sides has taught me that meeting with reps, understanding their sales techniques and strategies, and treating them as allies can be can be very productive. We are all in the business of sales, and libraries have a strong symbiotic relationship with these individuals and their companies. Why not listen to and learn from sales professionals_-and let them listen to and learn from us-so together we can build the best possible library for our users?

\section{ACKNOWLEDGEMENTS}

The author wishes to thank the following former colleagues for their valuable insights: Pamela Cowart, librarian and currently an Account Specialist, ProQuest; Timothy Fusco, 


\section{MANAGEMENT}

Vice President, Academic Sales, Gale, Cengage Learning; and Nancy Godleski, former account manager and currently Assistant Dean for Collections, Vanderbilt University.

\section{References and Notes}

1. Jennifer Smith, "First Year Law School Enrollment at 1977 Levels," Wall Street Journal, December 17, 2013, http://blogs.wsj.com/ law/2013/12/17/first-year-law-school-enrollment-at-1977-levels.

2. James Cash Penney's quote can be found in "Brainy Quotes," www.brainyquote.com/quotes/quotes/j/jamescashp226582.html.

3. This list includes reference, collection development staff, and teaching faculty. Increasingly, sales management is encouraging its sales force to meet with teaching and research faculty to better understand the environment in which the library operates and to uncover new information and research needs. This is not always a popular tactic from the librarian viewpoint.

4. A draw is an advance against anticipated commission. This model assumes a seasonality to sales and pays the rep on future commissions. The danger in the draw is that the sales person can end up owing the company money if insufficient sales are made. 